\title{
FRAGMENTOS DA HISTÓRIA DOS AFRO-DESCENDENTES EM PASSO FUNDO/RS ${ }^{1}$
}

\author{
Alessandro Batistella ${ }^{2}$
}

\begin{abstract}
Resumo: Embora alguns grupos étnicos de origem européia frequentemente sejam enaltecidos (em discursos oficiais, em publicações laudatórias ou mesmo em monumentos) como "responsáveis pelo desenvolvimento" de Passo Fundo, não se pode negligenciar a importância que determinados grupos étnicos subalternizados e deliberadamente esquecidos tiveram para a formação histórica da região norte do Rio Grande do Sul. Desta maneira, o presente artigo pretende abordar alguns fragmentos da história dos afro-descendentes em Passo Fundo.
\end{abstract}

Palavras chave: afro-descendentes; etnia; Passo Fundo.

\section{FRAGMENTS OF THE HISTORY OF AFRO-DESCENDANTS IN PASSO FUNDO/RS}

\begin{abstract}
Although some ethnic groups of European origin are often praised (rather in official speeches, in laudatory publications, or even in monuments) as "responsible for the development" of Passo Fundo, one can not neglect the importance that certain subaltern and deliberately forgotten ethnic groups have had for the Historical formation of the northern region of Rio Grande do Sul. In this way, the present article intends to address some fragments of the history of Afro-descendants in Passo Fundo.
\end{abstract}

Keywords: Afro-descendants; Ethnicity; Passo Fundo.

\section{FRAGMENTOS DE LA HISTORIA DE LOS AFRODESCENDIENTES EN PASSO FUNDO / RS}

Resumen: Aunque algunos grupos étnicos de origen europeo a menudo son enaltecidos (en discursos oficiales, en publicaciones laudatorias $\mathrm{o}$ incluso en monumentos) como "responsables del desarrollo" de Passo Fundo, no se puede descuidar de la importancia que determinados grupos étnicos subalternizados y deliberadamente olvidados para la formación histórica de la región norte de Rio Grande do Sul. De esta manera, el presente artículo pretende abordar algunos fragmentos de la historia de los afrodescendientes en Passo Fundo.

Palabras clave: afrodescendientes; origen étnico; Passo Fundo.

\footnotetext{
${ }^{1}$ Esse artigo teve a contribuição de Odorico José Ribeiro, músico percussionista e coordenador e integrante do Grupo Sambah! e do Grupo Cultural Alforria.

${ }^{2}$ Professor do Curso de História e do Programa de Pós-Graduação em História da Universidade de Passo Fundo (UPF). Doutor em História pela Universidade Federal do Rio Grande do Sul (UFRGS). E-mail: alessandrobatistella@yahoo.com.br
} 
Fronteiras: Revista de História

Fragmentos da História dos afro-descendentes em Passo Fundo/RS - Alessandro Batistella

\section{INTRODUÇÃO}

Embora alguns grupos étnicos de origem européia frequentemente sejam enaltecidos (em discursos oficiais, em publicações laudatórias ou mesmo em monumentos) como "responsáveis pelo desenvolvimento" de Passo Fundo, não se pode negligenciar a importância que determinados grupos étnicos subalternizados e deliberadamente esquecidos tiveram para a formação histórica da região norte do Rio Grande do Sul. Desta maneira, o presente artigo pretende abordar alguns fragmentos da história dos afro-descendentes em Passo Fundo.

Para tais propósitos, propomos inicialmente analisar a chegada dos afro-descendentes em Passo Fundo no século XIX na condição de escravos, cuja força-trabalho foi significativa para a economia local. Além de representarem cerca de $20 \%$ da população local na segunda metade do século XIX, os afro-descendentes, na condição de cativos ou libertos, contribuíram culturalmente para a sociedade passo-fundense, com lendas, crenças, ritos, festividades, etc. Desse modo, em um segundo momento, abordar-se-á dois patrimônios imateriais de Passo Fundo cujas origens remetem aos escravos afro-brasileiros: a lenda da Mãe Preta e a Romaria de São Miguel.

Em um terceiro momento, após a abolição da escravatura e a proclamação da República, focalizamos os anos finais do século XIX e as primeiras décadas do século XX, caracterizada pela inauguração da estrada de ferro e a chegada de várias famílias de afrodescendentes provenientes de outras regiões do estado e do país. No entanto, verificamos que a maioria dos afro-descendentes que viveram em Passo Fundo neste período tiveram poucas oportunidades de ascensão social e enfrentavam (e ainda hoje enfrentam) uma terrível herança escravocrata da nossa sociedade: o racismo.

Em virtude dos preconceitos étnicos e sociais, nas primeiras décadas do século $\mathrm{XX}$, os afro-descendentes de Passo Fundo eram proibidos de frequentar os outros clubes da cidade. Assim, organizaram uma sociedade étnica: o Clube Recreativo Visconde do Rio Branco, que será abordado na parte final do presente artigo. 


\section{A ESCRAVIDÃO E OS AFRO-DESCENDENTES EM PASSO FUNDO NO SÉCULO XIX}

Na condição de cativos, os afro-descendentes chegaram à região de Passo Fundo juntamente com os latifundiários milicianos ${ }^{3}$, que passaram a ocupar oficialmente a região a partir da década de 1820. Especificamente no local onde hoje se situa a cidade de Passo Fundo, o miliciano Manoel José das Neves, conhecido como Cabo Neves ${ }^{4}$, após obter a concessão no final de 1827 ou início de 1828, chegou à região trazendo consigo família, escravos e gado. Inicialmente, Cabo Neves fixou a sua moradia provisória junto a nascente do arroio que os índios conheciam por Goiexim (onde atualmente se localizam as esquinas das ruas Uruguai e Dez de Abril). Posteriormente, Cabo Neves edificou sua moradia definitiva nas proximidades da atual Praça Tamandaré, dando origem a uma modesta fazenda agropastoril $^{5}$ (D’ÁVILA, 1996, p. 49-52).

$\mathrm{Na}$ década de 1830, o local escolhido por Cabo Neves deu origem a um pequeno povoado, que servia de pouso para os tropeiros que percorriam a rota que ligava os campos de Vacaria a São Borja por meio do Planalto Médio. Na década de 1830, esse povoado, que passa a ser conhecido como Passo Fundo ${ }^{6}$, vai sendo lentamente ocupado, sobretudo por paulistas da Comarca de Curitiba.

Em 1847, ano em que o povoado de Passo Fundo - que formava o $4^{\circ}$ Distrito de Cruz Alta - foi elevado a condição de freguesia ${ }^{7}$, passando a denominar-se Freguesia de Nossa Senhora da Conceição do Passo Fundo, a população local era estimada em 1.159 pessoas (Rückert, 1997, p. 60). No entanto, como esse recenseamento era realizado pela Igreja católica, devemos salientar que esses números desprezavam os caboclos - que se encontravam

\footnotetext{
${ }^{3}$ Na região do Planalto Médio privilegiou-se a formação da grande propriedade a partir da concessão de amplas extensões de terras aos soldados a serviço da Coroa, que se tornarem estancieiros, dedicando-se, sobretudo, a pecuária, sem prescindir do uso de mão-de-obra escrava (SANTOS, 2009, p. 132).

${ }^{4}$ Nascido em Curitiba por volta do ano de 1790, Manoel José das Neves servia em um regimento de milícias na fronteira sul e lutou na Guerra Cisplatina (1825-1828), quando solicitou um lote de terras na região do "caminho das tropas", no Planalto Médio, junto ao comandante da fronteira em São Borja.

${ }^{5}$ No entanto, não se pode esquecer que, muito antes da chegada do Cabo Neves, a região já era ocupada pelos povos originários e por caboclos (RÜCKERT, 1997, p. 51-52).

${ }^{6} \mathrm{Na}$ região do Planalto Médio os tropeiros precisavam atravessar um rio chamado pelos kaingangs de Goio-En (que significa "rio fundo", "águas profundas" ou "muita água"), rebatizando-o como rio Passo Fundo - nome que deu origem à cidade.

${ }^{7}$ Naquela época, "freguesia" correspondia a população que vivia em torno de um templo católico, assistido por um padre. A passagem de "capela" a "paróquia", isto é, a elevação de povoado à freguesia, em virtude da nãoseparação entre Igreja e Estado nos tempos do Império, era um ato conjunto da administração civil e da administração eclesiástica.
} 
dispersos pelas zonas florestais e não frequentavam a igreja -, assim como a população indígena da região.

Ademais, também não se tem informações acerca do número de afro-descendentes escravizados ou libertos em Passo Fundo neste período. Contudo, não há dúvidas de que o trabalho escravo era utilizado em Passo Fundo, sobretudo nos latifúndios da região, pois, diante da baixa oferta da mão-de-obra livre, recorria-se a força de trabalho cativa para as mais diversas atividades rurais e urbanas.

Embora o trabalho escravo no Rio Grande do Sul tenha sido considerado ausente ou de menor importância por uma parcela da historiografia sul-rio-grandense, hoje tais argumentos foram amplamente refutados, uma vez que inúmeros trabalhos historiográficos, a partir do uso de novas fontes, sobretudo os inventários post-mortem e os relatórios das Câmaras Municipais, revelaram que a presença do escravo nas atividades rurais era mais importante do que se imaginava (ZARTH, 2006, p. 191-192).

O uso da mão-de-obra escrava na pecuária suscitou alguns debates na historiografia rio-grandense, parte dos autores defendeu que a escravidão não teve tanta importância nesse tipo de produção quanto nas produções do tipo plantation instaladas no centro e norte do país; e assim minimizam (ou pelo menos tentaram fazê-lo) a presença de africanos e seus descendentes na formação social do Rio Grande do Sul. De fato, a ausência de plantation típicas diminui o número de cativos no estado em comparação ao resto do país, e dificulta em parte a compreensão do modo como a mão-de-obra escrava foi utilizada no Rio Grande do Sul, mas sua presença não pode ser ignorada (SANTOS, 2009, p. 129).

Tabela 1 - Municípios com maior número de escravos no Rio Grande do Sul (1859)

\begin{tabular}{|l|c|c|c|c|}
\hline Município & População total & População livre & $\mathrm{N}^{\circ}$ de escravos & \% de escravos \\
\hline Porto Alegre & 38.140 & 29.723 & 8.417 & $22,06 \%$ \\
\hline Jaguarão & 18.055 & 12.999 & 5.056 & $28 \%$ \\
\hline Pelotas & 17.681 & 12.893 & 4.788 & $27,07 \%$ \\
\hline Rio Grande & 24.251 & 19.882 & 4.369 & $18,01 \%$ \\
\hline Cruz Alta & 30.503 & 26.484 & 4.019 & $13,17 \%$ \\
\hline Bagé & 16.358 & 12.342 & 4.016 & $24,55 \%$ \\
\hline
\end{tabular}

Fonte: ZARTH apud SANTOS (2009, p. 130). 
Sherol dos Santos (2009, p. 130) observa que embora as áreas de maior concentração de mão-de-obra cativa são as que possuem suas atividades econômicas ligadas a um centro urbano (Porto Alegre) ou às charqueadas (Jaguarão, Pelotas e Rio Grande), as regiões cuja principal atividade econômica era a pecuária (Cruz Alta e Bagé) também possuíam um contingente significativo de escravos, o que demonstra a importância do escravismo na atividade pastoril.

Henrique Kujawa (1998, p. 58-59) lembra que além do argumento de que o trabalhador escravizado era pouco utilizado no Rio Grande do Sul, também é comum encontrarmos em algumas obras o discurso do mito da democracia racial, que afirma que os poucos escravos que viviam no estado eram bem tratados, considerados iguais aos seus senhores, inclusive tomando chimarrão no mesmo galpão e na mesma cuia. Ainda segundo Henrique Kujawa (Ibidem, p. 59): "Pouco se sabe sobre a especificidade da relação entre escravos e senhores de escravos em Passo Fundo; as fontes oficiais não registravam e a historiografia regional, em grande parte, compactuou com o mito da democracia racial".

Salvo engano, os primeiros dados sobre o número da população de escravos em Passo Fundo foram obtidos por meio do recenseamento populacional de 1859 - realizado após a emancipação política de Passo Fundo, em 1857 -, no qual se constatou que os escravos representavam quase $20 \%$ da população local.

Tabela 2 - Número de escravos nos distritos de Passo Fundo (1859)

\begin{tabular}{|c|c|c|}
\hline Distrito & População do Distrito & $\mathrm{N}^{\mathrm{o}}$ de escravos no Distrito \\
\hline $1^{\text {o: }}$ Vila de Passo Fundo & 1.826 & 281 \\
\hline $2^{\circ}$ : Campo do Meio & 665 & 147 \\
\hline $3^{\circ}:$ Alto Uruguai & 464 & 79 \\
\hline $4^{\text {o: }}$ Jacuizinho & 1.310 & 315 \\
\hline $5^{\circ}:$ Restinga & 1.194 & 217 \\
\hline $6^{\mathrm{o}}:$ Soledade & 1.311 & 315 \\
\hline$\overline{7^{\circ}: \text { Lagoão }}$ & 1.451 & 345 \\
\hline Total & 8.221 & 1.699 \\
\hline
\end{tabular}

Fonte: RÜCKERT (1997, p. 89). 
Henrique Kujawa (1998, p. 59) faz duas importantes observações: primeiramente, ressalta que os dados oficiais não são precisos, pois os escravos muitas vezes não eram registrados; em segundo lugar, o autor lembra que o recenseamento de 1859 demonstrou que havia em Passo Fundo 127 ex-escravos, que foram libertados. Portanto, os afro-descendentes, na condição de escravos ou libertos, representavam uma significativa parcela da população local em meados do século XIX, o que comprova a utilização do trabalho escravo em Passo Fundo.

Analisando os inventários post-mortem de Passo Fundo entre os anos de 1850 a 1885, Sherol dos Santos (2009, p. 130-131) constatou que dos 148 documentos pesquisados, em 55,4\% deles os inventariados possuíam escravos. Ademais, a pesquisadora concluiu que o tamanho médio dos plantéis variou entre 1,08 (no período entre 1880 e 1885) e 5,04 escravos por propriedade (entre 1850 e 1855), sendo o maior plantel o de Maria Salomé, inventariado em 1854, onde foram arrolados 54 escravos.

Tabela 3 - Número de escravos nos inventários post-mortem de Passo Fundo

\begin{tabular}{|c|c|c|c|c|}
\hline Período & $\begin{array}{c}\text { Número de } \\
\text { inventários }\end{array}$ & $\begin{array}{c}\text { Número de } \\
\text { inventários com } \\
\text { escravos }\end{array}$ & $\begin{array}{c}\text { Total de } \\
\text { escravos nos } \\
\text { inventários }\end{array}$ & $\begin{array}{c}\text { Média } \\
\text { (escravos por } \\
\text { inventário) }\end{array}$ \\
\hline $1850-1855$ & 25 & $17(68 \%)$ & 126 & 5,04 \\
\hline $1860-1865$ & 38 & $27(71,05 \%)$ & 137 & 3,6 \\
\hline $1870-1875$ & 33 & $21(63,64 \%)$ & 111 & 3,36 \\
\hline $1880-1885$ & 52 & $17(32,7 \%)$ & 56 & 1,08 \\
\hline Total & 148 & $82(55,4 \%)$ & 430 & 2,91 \\
\hline
\end{tabular}

Fonte: SANTOS (2009, p. 131).

Ainda segundo a autora (2009, p. 131), os cativos arrolados nos inventários postmortem representavam uma significativa fração do patrimônio dos seus proprietários, revelando a importância do investimento em escravos em Passo Fundo, tornando-se uma mão-de-obra fundamental para a economia da região.

Portanto, não há dúvidas de que os latifundiários que se estabeleceram na região de Passo Fundo ao longo do século XIX utilizaram-se amplamente da mão-de-obra cativa, que desempenharam atividades como as de roceiros (lavradores de produtos de subsistência), Fronteiras: Revista de História | Dourados, MS |v. 19 | n. 34 | p. 353 - 372 | Jul. / Dez. 2017 
campeiros (trabalho pastoril) e domésticos (serviços rotineiros das casas e adjacências). O censo oficial de 1872 indica que no município de Passo Fundo, 299 escravos trabalhavam como lavradores, 255 como domésticos e 472 não tiveram sua atividade indicada. Contudo, também há indícios de que a força de trabalho cativa era empregada nos carijos, nas atafonas ${ }^{8}$ e nos engenhos de soque de erva-mate (RÜCKERT, 1997, p. 89-90).

Por outro lado, em Passo Fundo ocorreu a criação de dois quilombos na região do $3^{\circ}$ Distrito (o Alto Uruguai): trata-se dos quilombos de Arvinha e Mormaça, cujas comunidades remanescentes foram reconhecidas pela Fundação Cultural Palmares como descendentes da agregação de escravos e ex-escravos que ocuparam matas e campos no norte do Planalto RioGrandense $^{9}$ (OLIVEIRA, 2014, p. 19).

Imagem 1 - Mapa do município de Sertão, com a localização das comunidades quilombolas da Arvinha e da Mormaça

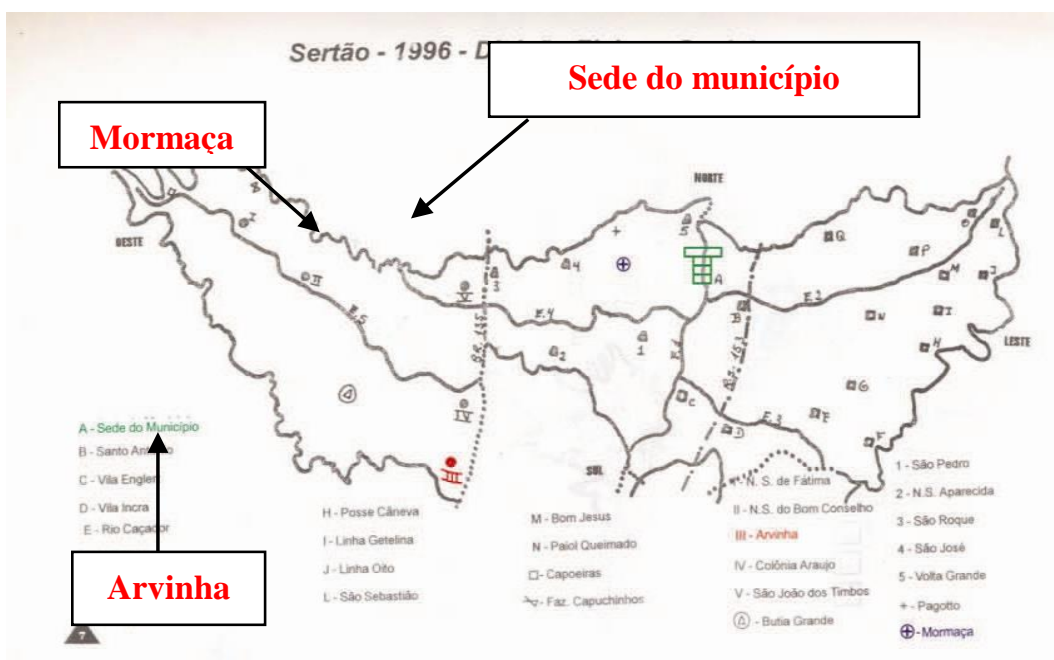

Fonte: OLIVEIRA (2014, p. 45).

De acordo com Heron Lisboa de Oliveira (2014, p. 45-46), o quilombo de Arvinha localizava-se na propriedade do coronel Francisco Barros de Miranda ${ }^{10}$, na atual zona rural

\footnotetext{
${ }^{8} \mathrm{~A}$ atafona era um moinho natural, movido por animais, onde se preparava farinhas de mandioca, milho e trigo.

${ }^{9}$ Heron Lisboa de Oliveira (2014, p. 19) lembra que a comunidade Mormaça foi reconhecida em 2004, enquanto a comunidade de Arvinha foi reconhecida em 2006.

${ }^{10} \mathrm{O}$ coronel Francisco Barros de Miranda era paulista radicado em Passo Fundo, latifundiário e importante membro da elite local. Proprietário da quase totalidade do então $3^{\circ}$ Distrito de Passo Fundo (Alto Uruguai), foi eleito juiz de paz no $3^{\circ}$ Distrito em 1860 , vereador em 1864 , comandou o $5^{\circ}$ Corpo da Guarda Nacional durante a Guerra do Paraguai (1864-1870). Foi um dos líderes do Partido Liberal em Passo Fundo. Foi casado com Maria
}

Fronteiras: Revista de História | Dourados, MS |v. 19 | n. 34 | p. 353 - 372 | Jul. / Dez. 2017 
dos atuais municípios de Sertão ${ }^{11}$ (em torno de $85 \%$ ) e Coxilha ${ }^{12}$. De acordo com o pesquisador, o nome Arvinha deve-se a existência de uma árvore, um pé de cambará no local.

A comunidade originou-se após a fixação na localidade da escrava Cezarina e sua família. Cezarina de Miranda era uma das escravas do coronel Miranda, que trabalhava nos serviços domésticos da "casa grande". A escrava Cezarina teve cinco filhos com o coronel Miranda, que doou a ela um lote de terras, onde atualmente está localizada a Comunidade Remanescente Quilombo da Arvinha (OLIVEIRA, 2014, p. 48).

Por sua vez, o quilombo da Mormaça localizava-se no interior das propriedades pertencentes ao coronel Francisco Barros de Miranda e dos seus cunhados, Amâncio de Oliveira Cardoso ${ }^{13}$ e Theobaldo Vieira ${ }^{14}$, no atual interior do município de Sertão. A origem da comunidade remete à escrava liberta Firmina ${ }^{15}$ e Elisbão Vieira ${ }^{16}$, que se instalaram com seus filhos - Cândida, Gervásio, Ottília, Laurentina, Francisca e Justimiano - nas matas que circundavam as propriedades destes três latifundiários ${ }^{17}$, uma vez que os laços de parentesco e aliança que uniam esses senhores facilitavam o trânsito dos seus escravos e agregados entre as suas propriedades (Cf. SANTOS, 2009, p. 135-136).

Prudência de Souza, que faleceu em 1876. No inventário de sua esposa, aberto em 1876, consta que o casal possuía 2.643 animais (entre eles destaca-se 1.284 reses de criar e 850 éguas) e oito escravos (três homens, quatro mulheres e uma criança). Entretanto, devido ao enorme tamanho da sua propriedade, é provável que o coronel Miranda possuísse um número mais elevado de escravos. O coronel Miranda faleceu em 1890, dois anos após a abolição da escravatura, em 1888, o que dificulta precisar o número de cativos que possuiu. (Cf. SANTOS, 2009, p. 133-134).

${ }^{11}$ Inicialmente integrante do $3^{\circ}$ Distrito de Passo Fundo, a emancipação e a criação do município de Sertão ocorreu em 1963.

${ }^{12}$ A emancipação e criação do município de Coxilha ocorrem em 1992.

${ }^{13}$ Amâncio de Oliveira Cardoso era filho adotivo de Maria Luiza de Oliveira (paulista e uma das primeiras proprietárias da região). Casou-se com Balbina Prudência de Souza, irmã de Maria Prudência de Souza, esposa do coronel Miranda. Foi por meio do seu casamento que Amâncio Cardoso fortaleceu seus vínculos com a elite local, o que lhe permitia uma maior participação política e sócio-econômica na sociedade local (Cf. SANTOS, 2009, p. 133-134). Vinculado ao Partido Liberal, liderado em Passo Fundo pelo major Antônio Ferreira Prestes Guimarães, Amâncio foi eleito vereador em 1872 e em 1882. Durante a Revolta Federalista (1893-1895) integrou as tropas federalistas. O coronel Amâncio de Oliveira Cardoso faleceu em 1904.

${ }^{14}$ Theobaldo Vieira era casado com Emilia Prudência de Souza (irmã de Maria Prudência de Souza e Balbina Prudência de Souza, esposas de Francisco de Miranda e Amancio de Oliveira, respectivamente).

${ }^{15}$ Firmina foi uma escrava doméstica, fiel e obediente que pertencia a Amâncio de Oliveira Cardoso, sendo alforriada - por motivos desconhecidos - em 1884, quando tinha aproximadamente 26 anos de idade e era mãe de três filhos: Cândida, Gervásio e Ottília (Cf. SANTOS, 2009, p. 135).

${ }^{16}$ Elisbão, que adotou o sobrenome "Vieira", provavelmente era um escravo ou um ex-escravo de Theobaldo Vieira (Cf. SANTOS, 2009, p. 136).

${ }^{17}$ Sherol dos Santos $(2009$, p. 137) observa que: "[...] Não é possível precisar o local exato onde a família se estabeleceu, seguramente à medida que as matas foram derrubadas e avançam sobre elas os campos de criação e lavoura, Firmina e Elisbão deslocam-se em busca de um lugar que pudessem abrigá-los com mais tranquilidade e segurança". 
Segundo Sherol dos Santos (2009, p. 137), as famílias de Firmina e Elisbão provavelmente não foram as únicas a buscar refúgio nas matas da região do $3^{\circ}$ Distrito, principalmente após a abolição da escravatura, em 1888.

Considerando o tamanho médio das propriedades no $3^{\circ}$ Distrito e a presença de escravos em maioria delas, podemos afirmar que os fazendeiros locais utilizavam seus agregados como posteiros ${ }^{18}$ e que ex-escravos faziam parte desse grupo. A doação de terras e de benfeitorias feita aos libertos ou a permissão para ocupá-las contemplava o interesse senhorial em legitimar a posse e o domínio sobre as terras que, não raro, eram objeto de intensas disputas (SANTOS, 2009, p. 136).

O nome "quilombo da Mormaça" deve-se á sua líder, Francisca Vieira (filha de Firmina e Elisbão Vieira), conhecida como "Chica Mormaça” (Cf. OLIVEIRA, 2014, p. 48$52)$.

Se por um lado os memorialistas locais não deram a devida atenção à questão da escravidão em Passo Fundo, por outro lado enfatizam a história do abolicionismo na cidade ${ }^{19}$, enaltecendo, assim, a "piedade do povo passo-fundense", sensibilizado com as agruras da condição servil, compactuando, dessa forma, com o mito da democracia racial.

De qualquer forma, apesar da referida campanha abolicionista no município - que obteve poucos resultados -, há que se ressaltar que

[...] em nenhum momento é questionada a discriminação do negro, tampouco se propõe formas de integração deles à sociedade. Portanto, também em Passo Fundo, como de resto em nível nacional, a abolição da escravatura ficou longe de representar a libertação do negro. Ele foi jogado à mercê da sociedade, sofrendo todo tipo de discriminação, só voltando a ser lembrado como agente histórico quando se discute a marginalidade e a violência da sociedade atual (KUJAWA, 1998, p. 59-60).

Em suma, após a abolição da escravidão, os afro-descendentes continuaram sofrendo com as nefastas heranças escravocratas, sobretudo com o racismo e a invisibilidade social. De fato, às margens da sociedade, com poucas oportunidades de educação e ascensão social, a eles foi designada uma condição de subcidadania. E mais, além das discriminações étnicas e

\footnotetext{
${ }^{18}$ Indivíduo que instalado estrategicamente na extremidade de uma propriedade, zela por sua integridade.

${ }^{19}$ De acordo com Delma Gehm (1978), em agosto de 1871 foi criada a Sociedade Emancipadora das Crianças do Sexo Feminino. Alguns outros autores referem-se a essa entidade como Sociedade Emancipadora Passofundense.
} 
sociais, os afro-descendentes ainda enfrentam os preconceitos às religiões de matriz africana $^{20}$.

Particularmente em Passo Fundo, a deliberada construção de uma história oficial e de uma memória etnocêntrica - de valorização do imigrante europeu - procurou minimizar a importância e a contribuição dos afro-descendentes, dos indígenas e dos caboclos para a história, a memória, a cultura e a identidade local. Entretanto, esses "excluídos da história" tiveram um importante papel na formação de Passo Fundo. Especificamente sobre os afrodescendentes, foco deste artigo, é indiscutível a sua importância para a história e para a cultura local. A seguir, iremos abordar dois patrimônios imateriais de Passo Fundo, cujas origens remetem aos escravos afro-brasileiros: a lenda da Mãe Preta e a Romaria de São Miguel.

\title{
A LENDA DA MÃE PRETA E A ROMARIA DE SÃO MIGUEL ARCANJO: PATRIMÔNIOS IMATERIAIS PASSO-FUNDENSES DE ORIGEM AFRO- BRASILEIRA
}

A lenda da Mãe Preta tem sua origem ligada a uma escrava do Cabo Neves, supostamente chamada de Mariana:

\begin{abstract}
Diz-se que Mãe Preta era escrava do Cabo Manuel José das Neves, que primeiro aqui se estabeleceu e era senhor daquelas glebas. Mãe Preta tinha um filho único, que era a sua alegria. Certa vez, o jovem fugiu de casa e não voltou, causando a morte de sua mãe. Das lágrimas da Mãe Preta teria brotado a fonte. Antes de morrer, Mãe Preta foi visitada por Jesus-menino, o qual lhe disse que não chorasse mais, porque seu filho se encontrava na mansão celeste. Jesus ter-lhe-ia dito ainda: em recompensa de tua dor, pede o que quiseres que de darei. Mãe Preta então pediu: dá-me a felicidade de ir para junto de meu filho. Mas, como lembrança, quero deixar esta fonte para que todo aquele que a beba retorne sempre a este lugar (CAFRUNI, 1966, p. 76-77).
\end{abstract}

No entanto, a lenda da Mãe Preta provavelmente se originou a partir de uma lenda kaingang, segundo a qual a Mãe Goiexim tinha um filho que guardava os ervais e certo dia foi à sua guarda e não mais voltou. A sua mãe chorou tanto a ausência do filho que o Urubu-Rei a transformou num pé de milho, que, arrancado pela tribo, deu origem a um arroio, pelo qual fluía a alma de Goiexim (CAFRUNI apud BATISTELLA; BACCIN, 2016, p. 112-113).

\footnotetext{
${ }^{20}$ Acerca das religiões de matriz-africana em Passo Fundo, ver SABINO (2016, p. 42-46). 
O arroio Goiexim, localizado nas terras posteriormente doadas pelo Cabo Neves, também passou a ser conhecido como arroio Lavapés e foi utilizado tanto pelos tropeiros quanto pela comunidade local. Em suas nascentes foi erguido, em 1863, um chafariz (ou uma bica), que serviu para o abastecimento de água da Vila de Passo Fundo, transportado pelos escravos, que iam ao local buscar a água que abastecia as casas dos seus senhores. Por esse motivo, em meados do século XIX, o local também ficou conhecido como "chafariz dos escravos do arroio Lavapés" (BATISTELLA; BACCIN, 2016, p. 113).

Portanto, a lenda kaingang da Mãe Goiexim foi apropriada, reelaborada e ressignificada pelos escravos afro-brasileiros que constantemente iam ao arroio Lava Pés buscar água, dando início a lenda da Mãe Preta.

Acerca da construção do chafariz do arroio Lava Pés (que passaria a ser conhecido como chafariz da Mãe Preta), consta que a primeira construção data de 1863. Posteriormente, em 1925, durante a administração do intendente Armando Araújo Annes, o chafariz foi reconstruído, com muros de proteção, bicas, telhado e os tanques para o trabalho das lavadeiras (a maioria delas afro-brasileiras) (BATISTELLA; BACCIN, 2016, p. 113).

\section{Imagem 2 - Chafariz da Mãe Preta (em 1930).}

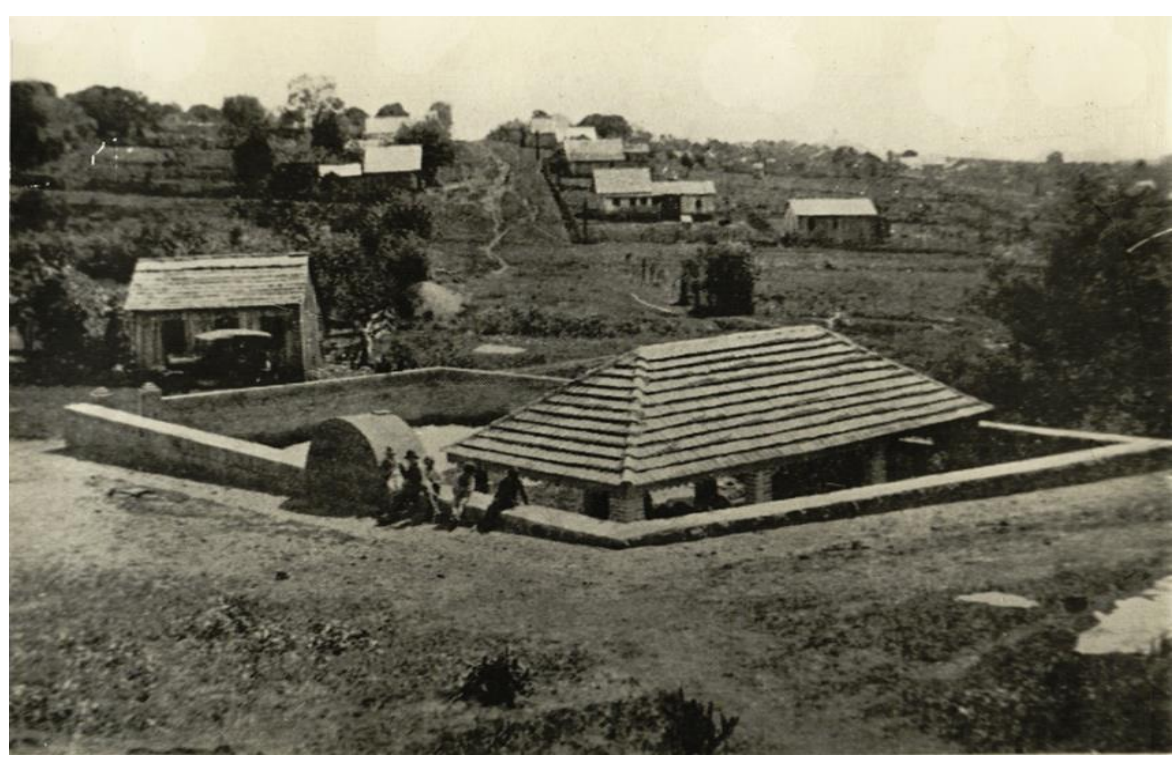

Fonte: acervo iconográfico do Museu Histórico regional.

Em 1963, durante a gestão do prefeito Mário Menegaz, o chafariz foi restaurado. Porém, em 1965, os moradores da região solicitaram a sua demolição e a remoção dos 
tanques, alegando que o mesmo estava obstruído as ruas Uruguai e Dez de Abril. Apesar da grande repercussão que o tema tomou junto à sociedade passo-fundense, o chafariz da Mãe Preta foi demolido sob a justificativa de ser um obstáculo ao "progresso e ao desenvolvimento do bairro" (BATISTELLA; BACCIN, 2016, p. 115-121).

Somente após 17 anos, em 1982, o chafariz foi reconstruído juntamente com um busto representando a Mãe Preta, localizando-se não mais no meio das ruas Uruguai e 10 de abril, mas recuado em uma praça, denominada Praça da Mãe Preta.

Imagem 3 - Chafariz da Mãe Preta (em 2017)

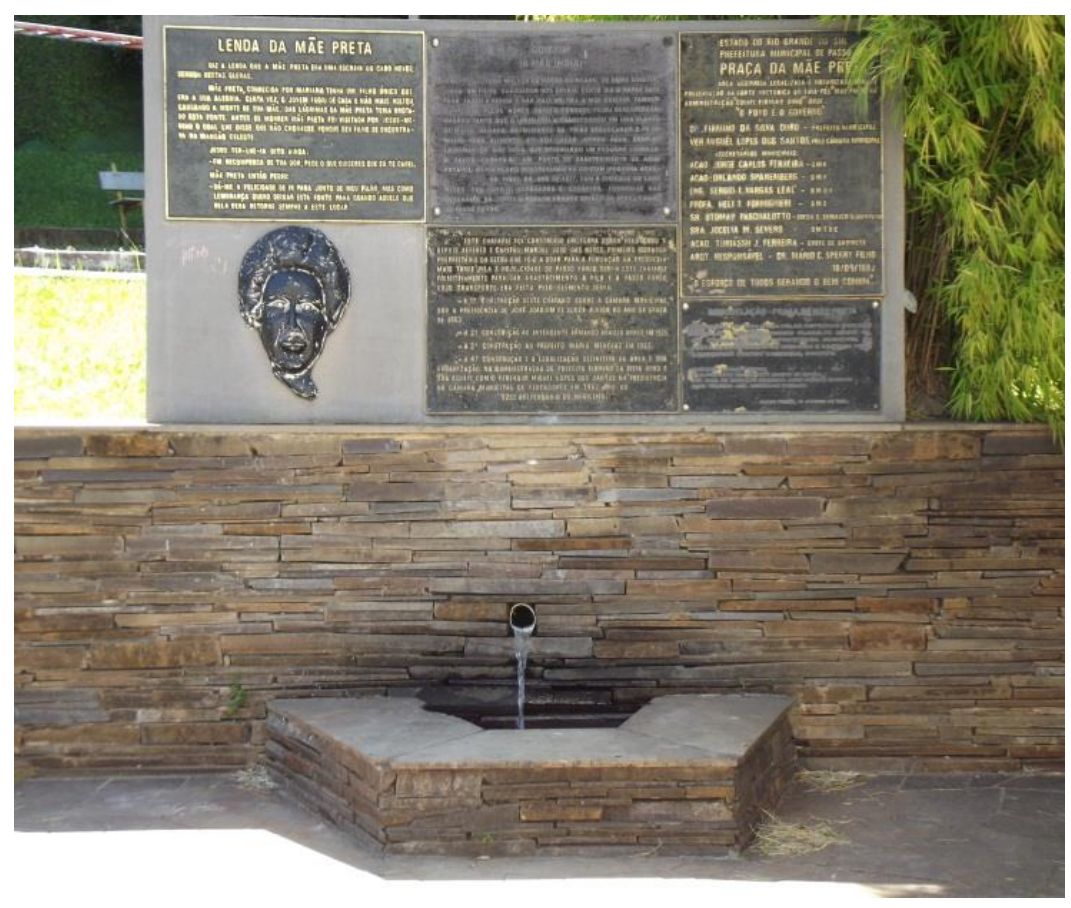

Fonte: acervo do autor.

A lenda da Mãe Preta é um dos principais patrimônios imateriais de Passo Fundo. Em uma cidade em que os afro-brasileiros são geralmente esquecidos pela memória e pela história oficial, o chafariz/monumento representa um dos raros casos na cidade de um patrimônio histórico-cultural de origem popular e um monumento que não seja associado à memória das elites locais. Contudo, há de se ressaltar que a lenda, ressignificada pelos afrobrasileiros locais, é de origem kaingang, cuja memória ainda encontra-se deliberadamente silenciada.

Por sua vez, a romaria de São Miguel Arcanjo teve início em Passo Fundo em 1871, 
após a construção da primeira capela em Pinheiro Torto (atual distrito de Pulador) pelos exescravos Generoso e Isaías, que pertenciam ao latifundiário Bernardo Castanho da Rocha, cujas terras localizam-se na região do Pinheiro Torto. De acordo com a tradição oral, Generoso e Isaías serviram como praças no $5^{\circ}$ Corpo de Cavalaria da Guarda Nacional durante a Guerra do Paraguai (1864-1870). Quando retornavam da guerra, teriam passado pelas imediações das ruínas das Missões de São Miguel, onde teriam encontrado a estátua do arcanjo, trazendo-a a Passo Fundo. Quando regressaram ao Pinheiro Torto, empreenderam a construção de uma pequena capela de pau-a-pique para abrigar a estátua de São Miguel. Posteriormente, essa primeira capela foi substituída por outra maior (GUIDOLIN; WINTER; ZANOTTO, 2011, p. 194).

Imagem 4 - Capela de São Miguel, localizada no distrito do Pulador (2017)

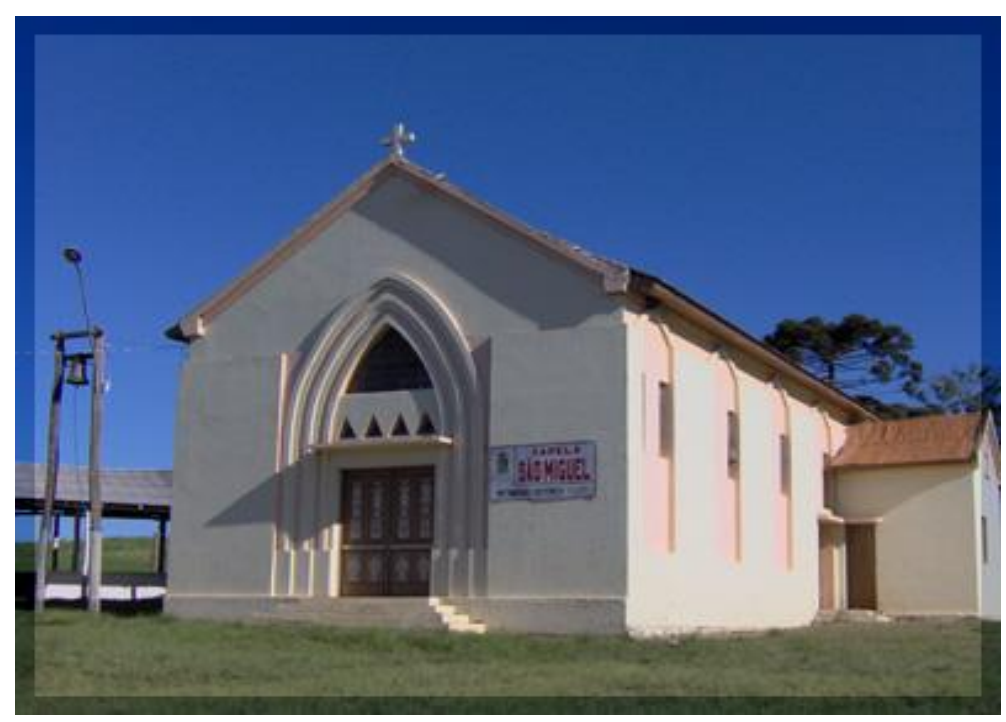

Fonte: www.guiafaciltur.com.br 
Imagem 5 - Estátua missioneira de São Miguel Arcanjo, exposta na Capela de São Miguel (2017)

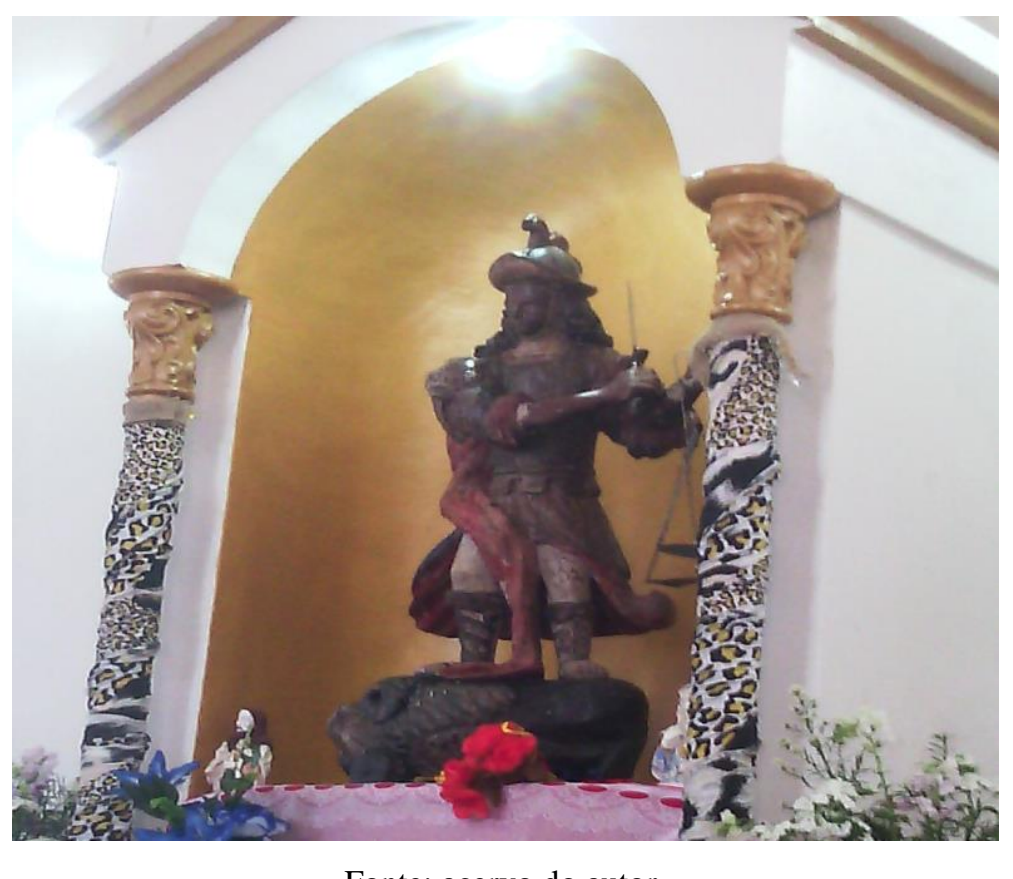

Fonte: acervo do autor.

Em 25 de outubro de 1991, por meio da lei no 2696/91, a Prefeitura Municipal de Passo Fundo tombou ${ }^{21}$ a Capela de São Miguel como patrimônio histórico-cultural do município. A referida capela é o ponto de chegada da tradicional romaria, que ocorre anualmente na cidade desde 1871.

\section{A FERROVIA E A CHEGADA DE NOVAS FAMÍLIAS DE AFRO-DESCENDENTES EM PASSO FUNDO}

Em fevereiro de 1898 concluiu-se a construção da estrada de ferro que ligava Passo Fundo a Cruz Alta, Santa Maria e Porto Alegre ${ }^{22}$.

\footnotetext{
${ }^{21}$ A palavra tombar é uma herança do direito português, cujo sinônimo é demarcar. Em outras palavras, o termo tombo foi designado como o registro e a catalogação de bens materiais e culturais, reconhecendo-os como integrantes do patrimônio histórico-cultural nacional, estadual ou municipal. Portanto, o processo de tombamento é um instituto jurídico que identifica os bens materiais e/ou culturais que serão obrigatoriamente protegidos (MACHADO, 2004, p. 20).

${ }^{22}$ Em 1889, o governo imperial idealizou a construção de uma ferrovia que ligasse São Paulo ao Rio Grande do Sul. Dessa forma, em 1891 foram aprovados estudos para a construção do trecho Santa Maria - Cruz Alta Passo Fundo - Marcelino Ramos, que permitiria a ligação com a rede férrea Paraná-Santa Catarina e Itararé-São Paulo. Em novembro de 1894 foi inaugurado o primeiro trecho, com 160 km, entre Santa Maria e Cruz Alta. Em fevereiro de 1898, o trecho Santa Maria - Cruz Alta -Passo Fundo foi concluído (Cf. TEDESCO, 2015).
}

Fronteiras: Revista de História | Dourados, MS |v. 19 | n. 34 | p. 353 - 372 | Jul. / Dez. 2017 
Imagem 6 - Mapa da malha ferroviária do Rio Grande do Sul (c. 1925)

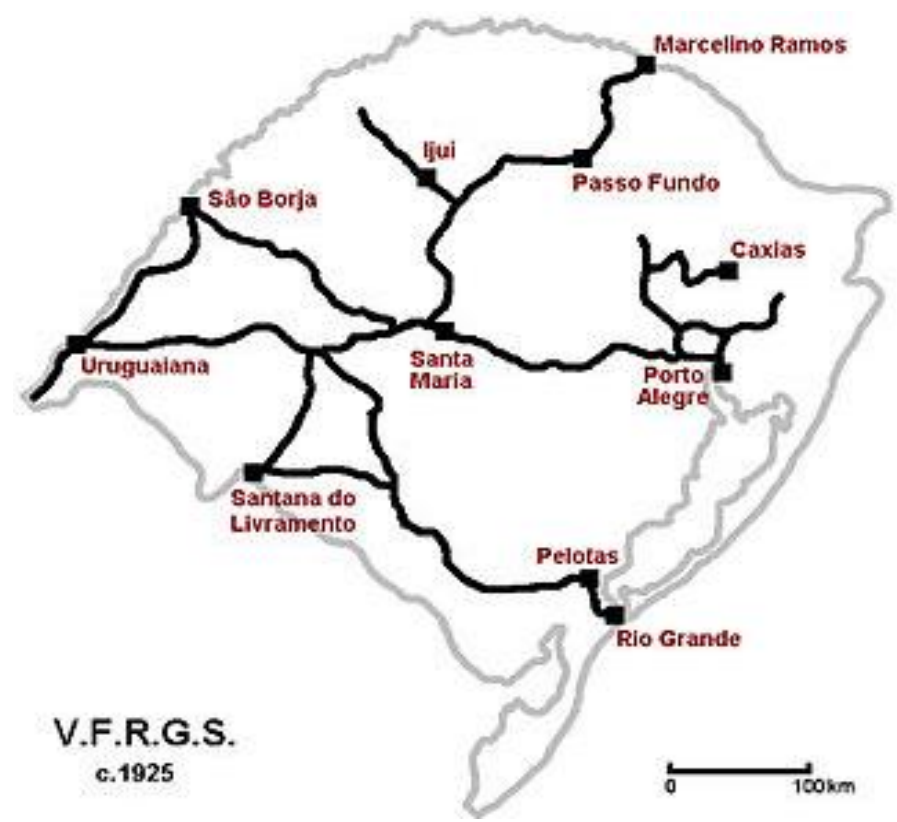

Fonte: https://upload.wikimedia.org/wikipedia/commons/7/74/VFRGS_Mapa.jpg

A conclusão da ferrovia foi fundamental para Passo Fundo, contribuindo decisivamente para o crescimento populacional da cidade e para a o desenvolvimento da economia local, impulsionando os setores hoteleiros, madeireiros, moageiros, granjeiros e o comércio local (Cf. TEDESCO, 2015).

Por meio do transporte ferroviário, muitas famílias de afro-descendentes provenientes de outras cidades do estado e do país - o começaram a se fixar em Passo Fundo no começo do século XX. Inclusive, muitas destas famílias eram de ferroviários e operários que trabalharam na construção da estrada de ferro.

Desde o final do século XIX e nas primeiras décadas do século XX, a maioria das famílias de afro-descendentes que residiam em Passo Fundo fixavam-se no bairro Boqueirão. De acordo com Edy Isaias (1999, p. 51-53), as famílias mais antigas que residiam neste bairro eram Almeida, Isaías, Severo e Bernardo da Cruz. Ainda segundo Isaias (Idem), naquela época poucas famílias de afro-descendentes não residiam no Boqueirão, dentre estas a família de Pedro Dionísio Navarro e Dona Romana - que residiam na rua Independência - e a família Lima.

Nas primeiras décadas do século XX, os afro-descendentes se dedicavam às mais diversas atividades econômicas na cidade, trabalhando como ferroviários, militares, 
comerciários, charqueadores ${ }^{23}$, marceneiros, alfaiates, barbeiros, motoristas, pintores, pedreiros, metalúrgicos, operários, entre outros ofícios. Também era comum que as mulheres trabalhassem como "lavadeiras" e empregadas domésticas. No entanto, poucos afrodescendentes conseguiam abrir uma pequena casa comercial ou tinham formação superior atuando, assim, como farmacêuticos, advogados, médicos, professores, jornalistas, entre outras profissões liberais.

Sem dúvida, os afro-descendentes que viveram em Passo Fundo no início do século XX sofreram fortemente as heranças escravocratas de nosso país, sobretudo com o racismo. De fato, em virtude dos preconceitos étnicos e sociais, nas primeiras décadas do século XX, os afro-descendentes de Passo Fundo eram proibidos de frequentar os outros clubes da cidade, como a Sociedade Italiana (fundada em 1901) ${ }^{24}$, o Clube Comercial (fundado em 1912) e a Sociedade Alemã (fundada em 1913) ${ }^{25}$. Assim, organizaram uma sociedade étnica: o Clube Recreativo Visconde do Rio Branco.

\section{O CLUBE VISCONDE DO RIO BRANCO}

Oficialmente fundado em abril de 1916, os relatos orais lembram que o Clube Visconde do Rio Branco teve a sua origem ligada a uma associação étnica e recreativa denominada Sociedade José do Patrocínio, fundada em 1912. Após quatro anos e algumas mudanças no seu nome, a referida associação passou a se denominar Clube Recreativo Visconde do Rio Branco.

A primeira sede do Clube Visconde do Rio Branco era uma enorme casa de madeira localizada a uma quadra e meia de distância da atual sede (localizada nas esquinas das ruas Morom e 20 de Setembro), inaugurada em 1932 (ISAÍAS, 1999, p. 48).

\footnotetext{
${ }^{23}$ Localizado na região do Umbu, próximo ao distrito do Pulador, o Saladeiro São Miguel manteve as suas atividades entre os anos de 1914 a 1932. Mais detalhes, ver o artigo de Sandra Mara Benvegnú (2010).

${ }^{24}$ Em 1938, em virtude da Lei de Nacionalização do Estado Novo (1937-1945), a Sociedade Italiana passou a se chamar Clube Caixeiral.

${ }^{25}$ Em 1938, também em virtude da Lei de Nacionalização do Estado Novo, a Sociedade Alemã transformou-se no Clube Recreativo Juvenil.
} 
Imagem 7 - Sede do Clube Visconde do Rio Branco, inaugurada em 1932

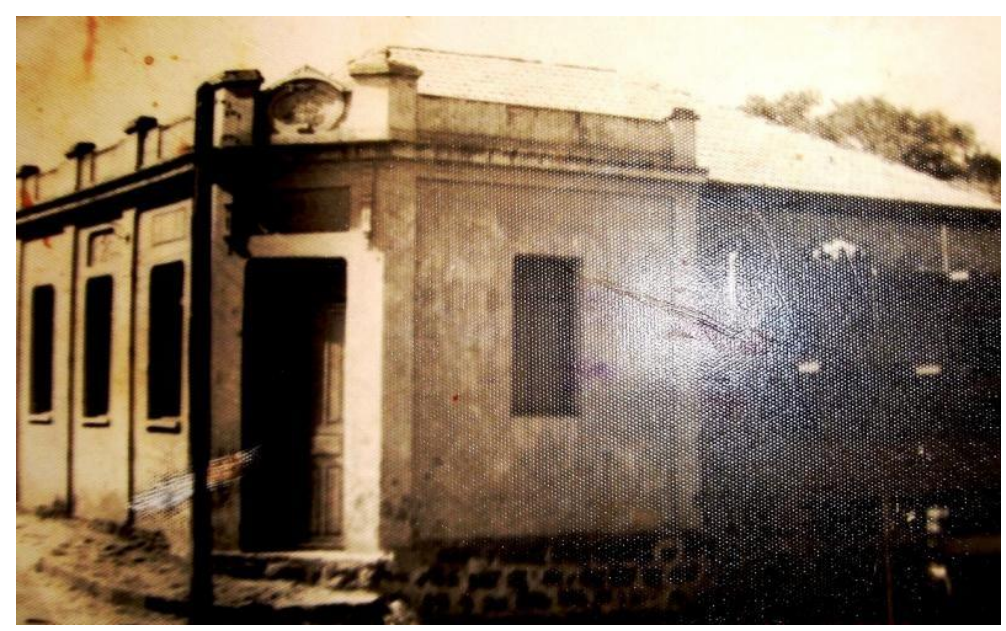

Fonte: acervo iconográfico do Museu Histórico Regional.

No Clube Visconde do Rio Branco eram comuns os encontros, as socializações, as festas (como, por exemplo, os casamentos, aniversários e os bailes de debutantes), as danças, os jogos, entre outras atividades recreativas e culturais. Contudo, uma das atividades culturais mais famosas promovidas pelo Clube Visconde do Rio Branco durante o século XX foram as festividades populares de carnaval, que atraiam pessoas de todas as etnias e classes sociais.

Nas primeiras décadas do século XX eram comuns em Passo Fundo os carnavais em alguns clubes ou sociedades, assim como também bailes à fantasia, matinês infantis, concursos de beleza e, sobretudo, os desfiles dos blocos carnavalescos e dos corsos (carros alegóricos) pelas praças e ruas centrais da cidade, onde ocorriam guerras de flores, confetes e serpentinas.

Havia uma grande rivalidade entre os blocos carnavalescos em Passo Fundo. Nesta época destacavam-se o Bloco 21 (que representava o Sport Club Gaúcho), o Bloco 25 (que representava o Clube Comercial e o Grêmio Esportivo Recreativo 14 de Julho) e o Bloco 33 da Pontinha (vinculado ao Clube Visconde do Rio Branco e criado no final da década de 1920), entre inúmeros outros. Cada bloco desfilava pelas ruas da cidade com seu estandarte e entoando as suas marchinhas.

Na década de 1950, o Clube Visconde do Rio Branco organizou a primeira escola de samba da cidade, que desfilava, juntamente com os outros blocos carnavalescos, pelas ruas de Passo Fundo. Também na década de 1950, surgiu em Passo Fundo a Escola de Samba Garotos da Batucada, que se originou a partir de uma dissidência do Visconde do Rio 
Branco. A Escola Garotos da Batucada foi formada pelas famílias Dionísio Navarro e Gradin $^{26}$. Posteriormente, na década de 1970, outras dissidências levaram ao surgiram de mais duas escolas de samba em Passo Fundo: a Bonsucesso (1971) e os Particulares do Ritmo $(1977)^{27}$

Nas décadas de 1970 e 1980, as escolas de samba de Passo Fundo organizaram concorridos desfiles de carnaval. Disputavam o carnaval passo-fundense o Visconde do Rio Branco, os Garotos da Batucada, a Bonsucesso, os Particulares do Ritmo, o Clube Industrial, o Clube Juvenil, o Clube Comercial, o Clube Caixeiral, entre outros. Nesta época ganharam destaque no carnaval da cidade a carnavalesca Djanira Ribeiro e o passista, mestre-sala e, sobretudo, mestre de bateria José Antônio Cavalheiro (conhecido como "Mestre Cavalheiro").

Entretanto, no início dos anos 1990, as escolas de samba do Visconde do Rio Branco e dos Garotos da Batucada deixaram de desfilar nos carnavais de Passo Fundo ${ }^{28}$. Em particular, o tradicional Clube Visconde do Rio Branco passou a enfrentar uma série de graves crises a partir da década de 1990. Atualmente, a sua sede encontra-se em ruínas.

Imagem 8 - Clube Visconde do Rio Branco (2017)

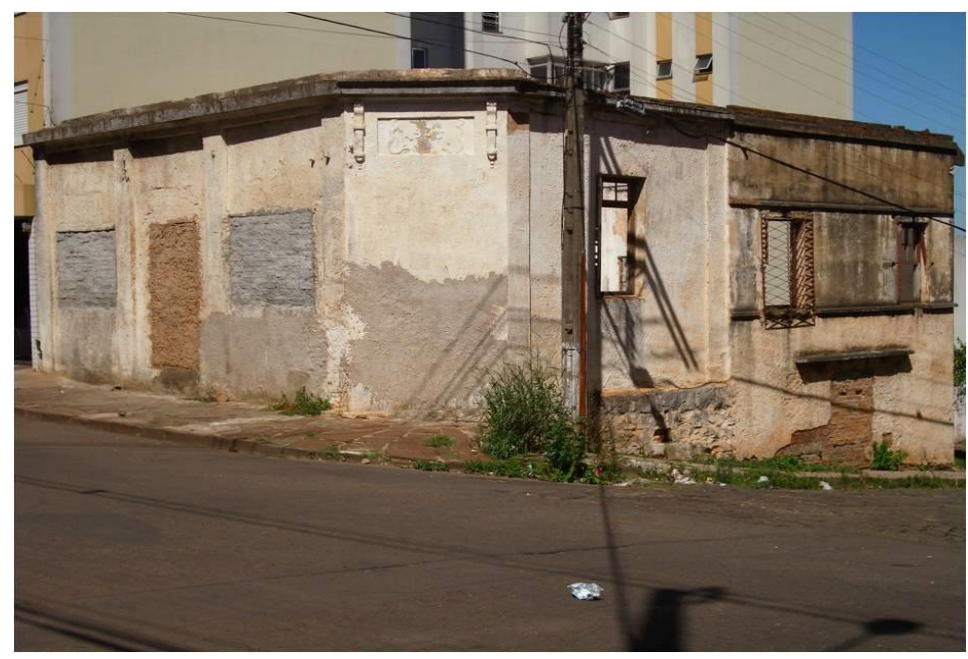

Fonte: acervo do autor.

\footnotetext{
${ }^{26}$ A Escola de Samba Garotos da Batucada, nos seus primeiros anos, ensaiava na rua Independência, onde morava a família Dionísio Navarro. Atualmente, a sua sede localiza-se à rua General Osório, no centro.

${ }^{27}$ A Escola de Samba Particulares do Ritmo foi fundada pela família Custódio. Sua sede localizava-se no bairro Rodrigues.

${ }^{28}$ Por outro lado, nesta época surgiram na cidade outras escolas de samba, como a Mocidade Independente, Bambas da Orgia, União da Vila, Imperadores do Samba, Pandeiro de Prata, Era de Aquários, entre outras. Atualmente, muitas destas escolas não desfilam mais no carnaval passo-fundense. Mais recentemente, no século XXI, surgiram outras escolas de samba em Passo Fundo, como a Academia de Samba Cohab I, Unidos da Operária e Acadêmicos do Chalaça.
}

Fronteiras: Revista de História | Dourados, MS | v. 19 | n. 34 | p. 353 - 372 | Jul. / Dez. 2017 
Fronteiras: Revista de História

Fragmentos da História dos afro-descendentes em Passo Fundo/RS - Alessandro Batistella

\section{CONSIDERAÇÕES FINAIS}

Embora muitas vezes estejam em uma situação de invisibilidade social, inclusive sofrendo com os preconceitos étnicos e sociais (e, por vezes, também religiosos), os afrodescendentes têm uma grande importância na formação histórica, socioeconômica, cultural e identitária de Passo Fundo. Vimos que durante o século XIX o trabalho escravo foi amplamente utilizado em Passo Fundo e os afro-descendentes, na condição de cativos ou libertos, representavam uma significativa parcela da população passo-fundense.

Também convém ressaltar que dois importantes patrimônios imateriais de Passo Fundo remetem ao período da escravidão e são de origem afro-brasileira: a lenda da Mãe Preta e a romaria de São Miguel.

Por fim, procuramos abordar alguns fragmentos da história do centenário Clube Visconde do Rio Branco, que constitui um importante patrimônio histórico-cultural de Passo Fundo e que ainda hoje catalisa sentimentos e faz emergir lembranças dos seus antigos frequentadores, que sonham em restaurá-lo e transformá-lo em um centro cultural. Porém, sem recursos financeiros, torna-se fundamental o apoio da Prefeitura Municipal para que esse sonho se torne realidade.

\section{REFERÊNCIAS BIBLIOGRÁFICAS}

BATISTELLA, Alessandro; BACCIN, Diego José. História, memórias e representações: uma análise dos monumentos em Passo Fundo. Passo Fundo: IFIBE/Saluz, 2016.

BENVEGNÚ, Sandra Mara. O Saladeiro São Miguel. 2010. Disponível em http://www.projetopassofundo.com.br/principal.php?modulo=texto\&con_codigo $=45305 \&$ tipo $=$ texto. Acessado em 18-03-2017.

CAFRUNI, Jorge E. Passo Fundo das Missões: história do período jesuítico. Passo Fundo: [s.n.], 1966.

D’AVILA, Ney Eduardo Possapp. Passo Fundo, terra de passagem. Passo Fundo: Aldeia Sul, 1996.

GEHM, Delma Rosendo. Passo Fundo através dos tempos. Passo Fundo: Multigraf, 1978.

GUIDOLIN, Camila; WINTER, Murillo Dias; ZANOTTO, Gizele. Plasticidade ritual: um estudo de caso das romarias de Passo Fundo. In: BATISTELLA, Alessandro (Org.). 
Patrimônio, memória e poder: reflexões sobre o patrimônio histórico-cultural em Passo Fundo. Passo Fundo: Méritos, 2011.

ISAÍAS, Edy. Imigrantes africanos - sua história, cultura e tradições. In: VERZELETTI, Santo Claudino. A contribuição e a importância das correntes imigratórias no desenvolvimento de Passo Fundo. Passo Fundo: Imperial, 1999, p. 48-58.

KUJAWA, Henrique A. Formação étnica de Passo Fundo e região. In: DIEHL, Astor Antônio (Org.). Passo Fundo: uma história, várias questões. Passo Fundo: UPF, 1998.

MACHADO, Maria Beatriz Pinheiro. Educação Patrimonial: orientações para professores do ensino fundamental e médio. Caxias do Sul: Maneco, 2004.

OLIVEIRA, Heron Lisboa de. Comunidades remanescentes dos quilombos de Arvinha e Mormaça - processos educativos em manutenção e recuperação do território. Tese (Doutorado em Educação) - Universidade do Vale do Rio dos Sinos, São Leopoldo, 2014.

SABINO, Jeferson. Crenças afro-brasileiras. In: ZANOTTO, Gizele (Org.). Mapeamento do patrimônio imaterial de Passo Fundo/RS. Passo Fundo: Projeto Passo Fundo, 2016, p. 42-46.

SANTOS, Sherol dos. Territórios étnicos no pós-abolição: o caso do quilombo da Mormaça (RS). Fronteiras, Dourados, v. 11, n. 19, jan./jun. 2009.

RÜCKERT, Aldomar A. A trajetória da terra: ocupação e colonização do centro-norte do Rio Grande do Sul (1827-1931). Passo Fundo: UPF, 1997.

TEDESCO, João Carlos. A Gare e o trem em Passo Fundo: sinergias econômicas - 18981978. Porto Alegre: EST, 2015.

ZARTH, Paulo Afonso. A estrutura agrária. In: GOLIN, Tau; BOEIRA, Nelson (Orgs.). História geral do Rio Grande do Sul. Passo Fundo: Méritos, 2006, v. 2. 